\title{
ДЕТРИТОВЫЕ ЦИРКОНЫ ИЗ БАЗАЛЬНЫХ ТЕРРИГЕННЫХ ТОЛЩ НЕОАРХЕЙСКОГО И ПАЛЕОПРОТЕРОЗОЙСКИХ ПОЯСОВ ВОСТОЧНОЙ ЧАСТИ ФЕННОСКАНДИНАВСКОГО ЩИТА. ГЕОДИНАМИЧЕСКИЕ РЕКОНСТРУКЦИИ
}

\author{
Смолькин В.Ф. ${ }^{1}$, Межеловская С.В. ${ }^{2}$, Межеловский А.Д. ${ }^{3}$ \\ ${ }^{1}$ ГГМ РАН, Москва, v.smolkin@sgm.ru; \\ ${ }^{2}$ МГРИ-РГГРУ, Москва \\ ${ }^{3}$ ФГБУ ИМГРЭ, Москва
}

Одним из наиболее универсальных минералов-геохронометров является циркон. Высокая прочность и химическая устойчивость в широком диапазоне РТ_условий обусловливают его нахождение в виде детритовых зерен в терригенных породах - конгломератах, гравелитах, аркозах и кварцитах. Особая роль таких цирконов выявилась при реконструкции древних этапов формирования и преобразования континентальной коры.

Нами были опробованы и исследованы терригенные породы, залегающие в основании разрезов Урагубско-Титовского неоархейского зеленокаменного пояса, Печенгской зоны, являющейся частью Печенгско-Варзугской палеорифтогенной системы, и Ветреного пояса палеопротерозойского возраста. Ранее были исследованы цирконы из красноцветных гравелитов лучломпольской свиты, залегающих в средней части разреза Печенгской зоны [5] и терригенных пород токшинской свиты Ветреного пояса [3].

Вес проб составлял 5-8 кг. Извлечение и предварительное изучение циркона осуществлялось в лабораториях ВСЕГЕИ (УГ72, П73), ИГГД РАН (ТК-12-01) и ИГ КарНЦ РАН (П26).

$\mathrm{U}-\mathrm{Pb}$ изотопный анализ циркона из проб УГ-72 и П-73 выполнялся на SHRIMP-II (ссылки на методики анализа и программы обработки данных - см. [6]). Интенсивность первичного пучка молекулярных отрицательно заряженных ионов кислорода составляла 4 нА при размере пятна пробоотбора около $35 \times 2$ мкм. Обработка данных осуществлялась с использованием программы SQUID. U/Pb отношения нормализовались на значение 0.0668 , приписанное стандартному циркону TEMORA, что соответствует возрасту этого циркона 416.8 млн лет. Для определения концентраций $U$ и Th использовался стандарт циркона 91500 с известным содержанием $U=81.2$ ppm. Погрешности единичных анализов (отношений и возрастов) приводятся на уровне $1 \sigma$, погрешности конкордантных возрастов (по совокупности анализов) и пересечений дискордий с конкордией приводятся на уровне $2 \sigma$. Построение графиков с конкордией проводилось с использованием программы ISOPLOT/EX.
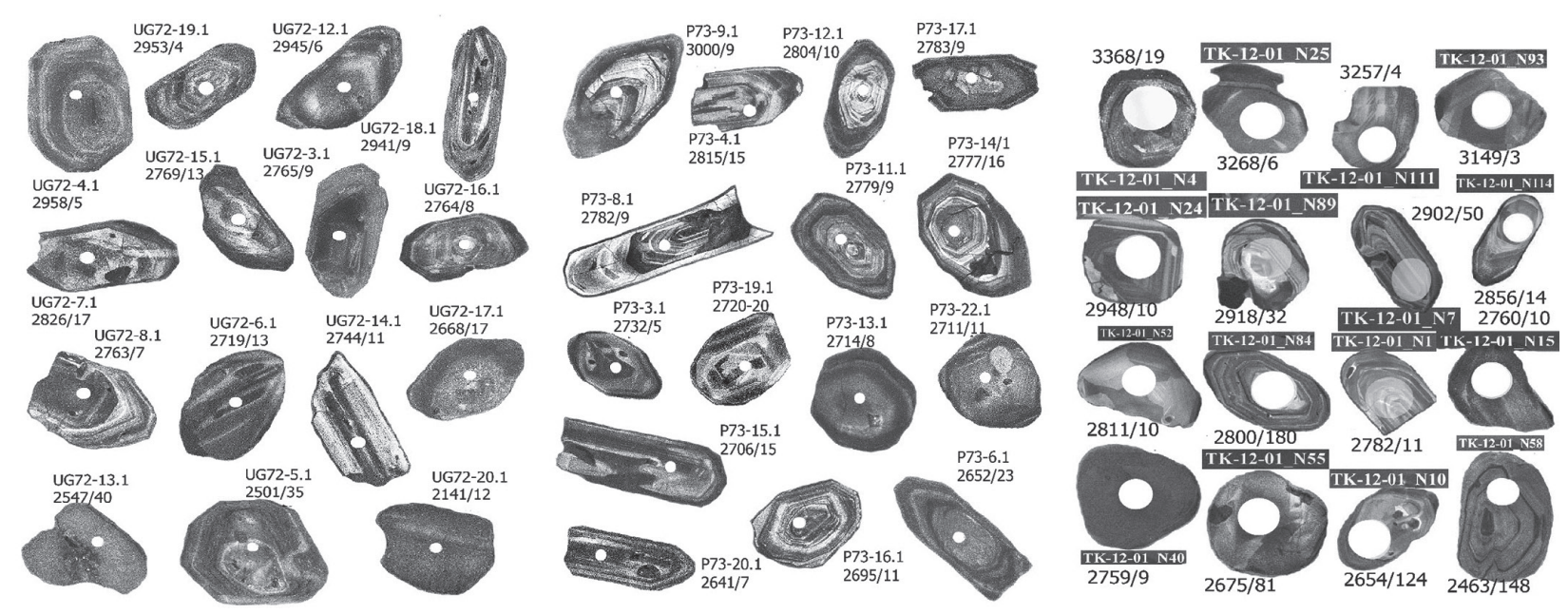

Рис. 1. CL-изображения зерен цирконов с номерами аналитических точек и изотопным возрастом из проб УГ72, П73 и ТК-12-01. 

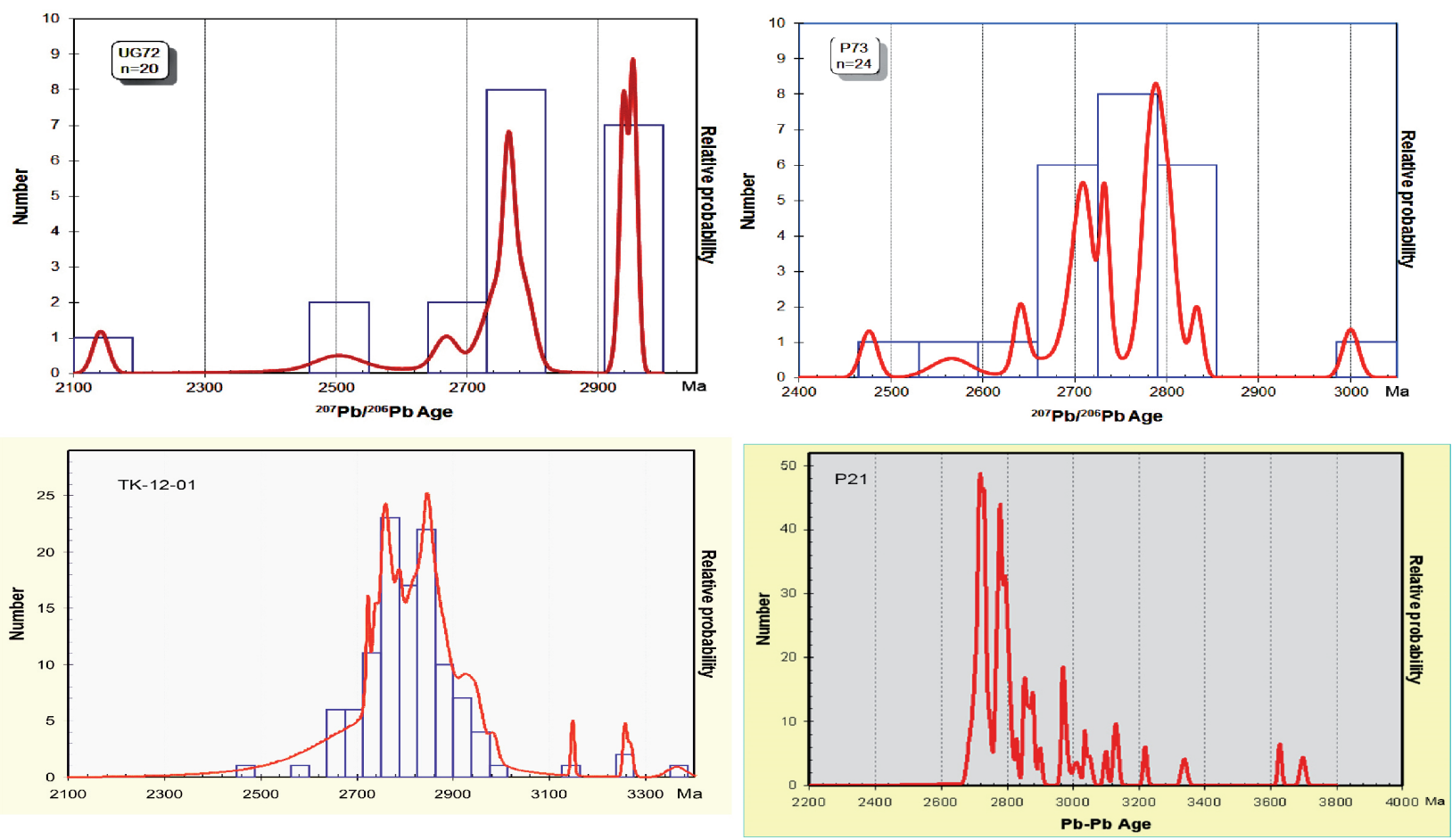

Рис. 2. Мультимодальное распределение ${ }^{207} \mathrm{~Pb} /{ }^{206} \mathrm{~Pb}$-возрастов на PD-диаграмме из проб УГ72, П73 и ТК-12-01.

Изотопный анализ циркона изпроб ТК-12-01 и П21 выполнено методом лазерной абляции DUV193 (NewWaveResearch) на основе 193 нм ArF эксимерного лазера COMPex-102 (LambdaPhysik) в сочетании с масс-спектрометрическими измерениями с ионизацией пробы в индуктивно-связанной плазме (LA-ICP-MS) на приборе ThermoFinnigan Neptune. Размер лазерного кратера составлял 50 мкм при глубине порядка 30-50 мкм, т.е. существенно больше, чем при U-Pb анализе на SHRIMP-II. Это обстоятельство определяет определенную сложность в сопоставлении U-Pb данных, полученных разными методами, для многофазных кристаллов цирконов.

Проба УГ72 отобрана в среднем течении р. Ура, на 8 км автодороги на пос. Видяево, на северозападном берегу озера. Материал пробы представляет собой мелкозернистый граувакковый цемент рассланцованных конгломератов, содержащих уплощенную гальку гранитов, гнейсов и кварца. Циркон слагает прозрачные и полупрозрачные, а также окрашенные в различные тона субидиоморфные и идиоморфные призматические кристаллы, слабоокатанные зерна и их обломки (рис. 1). Большинство зерен трещиноватые и содержат включения. Их длина составляет 152-400 мкм, Ку-1.3-3.4.

Большинство аналитических точек на изохронной диаграмме ${ }^{206} \mathrm{~Pb} /{ }^{238} \mathrm{U}-{ }^{207} \mathrm{~Pb} /{ }^{235} \mathrm{U}$ располагаются на конкордантной кривой. Основной кластер имеет ${ }^{207} \mathrm{~Pb} /{ }^{206} \mathrm{~Pb}$ возраст в интервале от 2670 до 2960 млн. лет с двумя четко выраженными пиками 2762 и 2939-2952 млн. лет (рис. 2). Для них построены дискордии с верхним пересечением $2763 \pm 8$ и $2948 \pm 10$ млн. лет. Отдельные зерна, точки которых располагаются выше кривой, характеризуются повышенным содержанием U (597-678 ppm). Для трех зерен установлены пониженные значения ${ }^{207} \mathrm{~Pb} /{ }^{206} \mathrm{~Pb}$ возраста $-2547,2504$ и 2141 млн. лет с большими ошибками определений (99-166). Эти данные, а также аномально высокие содержания $\mathrm{U}$ (1268-1712 ppm) или Th (1000 ppm) свидетельствуют о нарушении изотопной системы в результате привноса $\mathrm{U}$ или Th.

Проба П73 отобрана в Печенгском районе, на северном берегу оз. Питьевое, севернее г. Заполярный, из взрывной массы слабо отсортированных крупногалечных конгломератов телевинской свиты. Конгломераты залегают на тоналитовых гнейсах фундамента с U-Pb возрастом циркона $2752 \pm 12$ млн. лет [1]. В пробе присутствуют прозрачные и полупрозрачные, коричневые, желтые и желто-серые субидиоморфные призматические кристаллы и их обломки; часть кристаллов имеет тонкую или секториальную зональность (рис. 1). Размер по длине составляет 150-509 мкм, $\mathrm{Ky}=1.0-6.6$. 


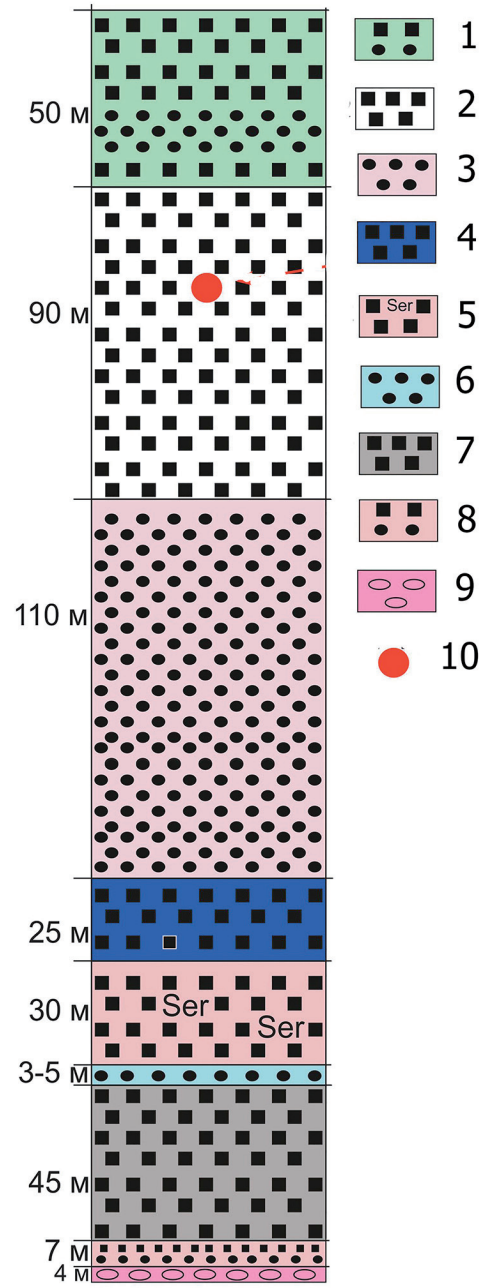

Рис. 3. Сводный разрез токшинской свиты по данным бурения мощностью 90 м по данным [2].

1 - кварциты и гравелиты с фукситом; 2 -белые кварциты; 3 - гравелиты; 4 - синие кварциты; 5 - розовые кварциты с серицитом; 6 - голубоватые кварциты; 7 - серые кварциты; 8 - молочно- розовые кварциты, гравелиты; 9 - полимиктовые, молассовидные конгломераты; 10 - место взятия пробы на изотопный анализ ТК-12-01.

Основная часть зерен циркона из пробы $П 73$ имеет ${ }^{207} \mathrm{~Pb} /{ }^{206} \mathrm{~Pb}$ возраст в интервале от 2700-2830 млн. лет с пиками 2707, 2731 и 2785 млн. лет (рис. 2). Для них построены дискордии с верхним пересечением конкордии с возрастами $2724 \pm 9$ и $2792 \pm 7$ млн. лет. Слабо выраженный пик имеет значение 2831 млн. лет. В этой же пробе было обнаружено зерно с возрастом $3009 \pm 9$ млн. лет, а также зерна с пониженными возрастными данными - 2640, 2566 и 2476 млн. лет с большой дискордией (22-64 \%). Зерно с возрастом 2476 млн. лет имеет высокое содержание U (1000 ppm) и аномально низкое отношение ${ }^{232} \mathrm{Th} / 238 \mathrm{U}=0.02$, что свидетельствует о метасоматическом преобразовании.

Ранее изученная Проба П21 [5] характеризует красноцветные аркозовые песчаники и гравелиты, залегающие на коре выветривания субщелочных вулканитов (2.3 млрд лет) и перекрытые красноцветными доломитами с биогермами строматолитов общей мощностью 80 - 150 м. Проба отобрана севернее пос. Никель, в районе среднего течения руч. Лучломполо. Зерна цирконов имеют округлую или овально-округлую форму и представляют собою хорошо окатанные обломки кристаллов с различным внутренним строением. Их размер по длине варьирует в пределах 50-140 мкм.

Все точки локального U-Pb анализа располагаются на конкордантной кривой. Основная часть зерен циркона из пробы П21 имеет ${ }^{207} \mathrm{~Pb} /{ }^{206} \mathrm{~Pb}$ возраст в интервале от 2700-2820 млн. лет с пиками 2715 и 2790 млн. лет, в подчиненном количестве встречаются зерна с возрастом в пределах 2840-3000 млн. лет, и отдельные зерна имеют более древний возраст - до 3700 млн. лет [5]. Наиболее древнее зерно с возрастом $3698 \pm 8$ млн. лет содержит ядро и широкую кайму с нечетко выраженной зональностью. Зерна с палеопротерозойским возрастом полностью отсутствуют. Это свидетельствуют о том, что вулканиты, слагающие нижнюю часть разреза не подверглись интенсивной эрозии.

Проба ТК-12-01 характеризует светлые кварциты, залегающие в верхней части 90-метрового разреза токшинской свиты в районе горы Двойная на территории Водлоозерского национального парка (рис. 3). Цирконы представлены короткопризматическими кристаллами с хорошо выраженной зональностью, округлыми окатанными зернами и их обломками (рис. 1). Часть зерен имеет блочное или относительно однородное строение. Их размер по длине находится в пределах 50-200 мкм.

Из 120 зерен проанализировано 114, для 90 зерен получены конкордантные возраста. Основная часть зерен циркона ( $80 \%)$ имеет ${ }^{207} \mathrm{~Pb} /{ }^{206} \mathrm{~Pb}$ возраст в интервале $2720-2885$ млн. лет с двумя четко выраженными пиками - 2758 и 2845 млн. лет (рис. 2). Для цирконов более древнего пика конкордантный возраст равен $2885 \pm 67$ млн. лет. Менее $20 \%$ цирконов имеют датировки в интервале 2010-2985 млн. лет с пиковым значением 2920 млн. лет. Единичные цирконы имеют более древние возраста 3148, 3257, 3357 млн. лет с ошибкой определения 1-5 \%. Были встречены также единичные цирконы с пониженными возрастами в интервале 2654-2463 млн. лет. Они имеют большую ошибку определения и большую степень дискордантности. 
Ранее для цирконов из разнообразных гнейсов и гранитоидов Северной Печенги и Северной Норвегии [1] были получены U-Pb возраста 2715-2725, 2752-2762, 2803-2825 и 2902 млн. лет [1], которые близки или совпадают с полученными данными. Более древнее вещество в виде ксеногенных цирконов с ${ }^{207} \mathrm{~Pb} /{ }^{206} \mathrm{~Pb}$ возрастом $3548 \pm 12$ и $3592 \pm 15$ млн. было обнаружено с гнейсах кольской серии с возрастом $2910 \pm 21$ млн. лет [4]. Наши данные удревняют возраст древнего субстрата - до 3.7 млрд. лет.

Необходимо отметить, что древние ксеногенные цирконы были встречены не только в осадочных терригенных породах, но и в магматитах палеопротерозойского возраста, например, в субвулканических интрузиях метагаббро-серпентинитов Кеулик-Кениримской структуры, в которых ${ }^{207} \mathrm{~Pb} /{ }^{206} \mathrm{~Pb}$ возраст ксеногенных цирконов равен 2654, 2784 и 3166 млн. лет [6]. Ксеногенные цирконы с возрастом до 3.8 млрд. лет были обнаружены также в вулканитах свиты ветреного пояса с возрастом извержения 2.4 млрд. лет [7].

\section{Выводы}

1. Неоархейские и палеопротерозойские пояса Кольско-Лапландско-Карельской провинции были заложены на коре континентального типа.

2. Наиболее древнее вещество сохранилось в виде реликтов с возрастом циркона 3.6-3.7 млрд. лет назад.

3. Основной вклад в континетальную кору дали гнейсы и гранитоиды различного состава с возрастом циркона 2.72-2.70, 2.79-2.76, 2.85-2.83, а также 2.95-2.90 млрд. лет.

4. Архейский Урагубско-Титовский зеленокаменный пояс был заложен около 2.72 млрд. лет и он является более молодым, чем зеленокаменные пояса Карелии.

5. По мере разрушения континентальной коры в результате ее подъема и эрозии в неоархейский и палеопротерозойский этапы вскрывались все более древние комплексы, часть из которых отсутствует на современном эрозионном срезе.

Работа выполнена при поддержке Программы РФФИ «Детритовые цирконы терригенных толщ Ветреного Пояса - как индикаторы условий формирования рифтогенных структур восточной части Фенноскандинавского щита в палеопротерозое»»» № 17-05-00592 А.

\section{Литература}

1. Ветрин В.Р. Протерозойские процессы магматизма и метасоматоза в архейских породах Печенгского палеорифта // Вестник МГТУ. Т. 10. № 1. 2007. С. 116-129.

2. Межеловская С.В., Корсаков А.К., Межеловский А.Д., Бибикова Е.В. Временной диапазон формирования осадочно-вулканогенного комплекса Ветреного Пояса // Стратиграфия и геологическая корреляция. 2016. № 2. С. 1-14.

3. Межеловская С.В., Межеловский А.Д. Вероятные источники обломочного материала при формировании кварцитов токшинской свиты Ветреного Пояса по данным анализа детритовых цирконов // Геология и разведка. 2014. № 5. С. 11-17.

4. Мыскова Т.А., Бережная Н.Г., Глебовицкий В.А. и др. Находки древнейших цирконов с возрастом 3600 млн. лет в гнейсах кольской серии Центрально-Кольского блока Балтийского щита (U-Pb, SHRIMP-II) // ДАН. 2005. Т. 402. № 1. С. 82-86.

5. Смолькин В.Ф., Кожевников В.Н., Капитонов И.Н. Первые результаты локального U-Pb датирования циркона (SHRIMP-II) из метаосадков и турбидитов Печенгской структуры и геодинамические реконструкции // Минералогия, петрология и полезные ископаемые Кольского региона. Tр. VIII Всероссийской (с международным участием) Ферсмановской научной сессии, посвященной 135-летию со дня рождения академика Д.С. Белянкина). Апатиты. Изд-во: К\& М. 2011. С. 208-213.

6. Смолькин В.Ф., Лохов К.И., Скублов С.Г. и др. Палеопротерозойский рудоносный габброперидотитовый комплекс Кеулик-Кенирим (Кольский регион) - новое проявление ферропикритового магматизма // ГРМ. 2018. Т. 60. № 2. С. 1-34.

7. Смолькин В.Ф., Шарков Е.В., Лохов К.Н., Капитонов И.Н., Сергеев С.А. Генезис высокомагнезиальных вулканитов Ветреного пояса палеопротерозоя по данным исследований U-Pb и Lu-Hf систем в цирконах (Восточная Карелия) // ДАН. 2011. Т. 439. № 4. С. 528-533. 